\title{
FINITE ELEMENT ANALYSIS OF HOLLOW-CORE SLABS
}

\author{
E. Frățilă ${ }^{\text {a, * }}$ Z. Kiss ${ }^{\text {a }}$ \\ ${ }^{a}$ Technical University of Cluj-Napoca, Faculty of Civil Engineering, 28. Memorandumului str. 400114, Cluj-Napoca, Romania
}

Received: 01.04.2016 / Accepted: 15.04.2016 / Revised: 20.05.2016 / Available online: 31.05.2016

DOI: 10.1515/jaes-2016-0003

KEY WORDS: experimental modal analysis, hollow-core slab, vibration, FE Analysis

\begin{abstract}
:
The use of high resistance materials in nowadays structures has led to an increase in the span of the floors. Despite meeting the resistance and deformation criteria, floors might vibrate excessively due to increased slenderness. Based on a real-scale model experimental program, a parametric study has been developed in order to asses the vibration performance of prestressed hollow-core slab system on spans larger than the ones on which tests have been conducted, and the interaction between the concrete that have been poured in different stages. The measurements have been performed using Brüel and Kjær equipment, whereas the study has been carried out using Abaqus 6.11. finite element software. The simulations have been made by increasing the span of the slab, in order to observe the variation of the fundamental frequency. Also, the simulations have been conducted with different types of concrete topping thickness. The minimum acceptable value of the fundamental frequency has been considered $8 \mathrm{~Hz}$, according to existing literature.
\end{abstract}

\section{INTRODUCTION}

\subsection{General considerations}

The use of hollow-core slabs in modern precast solutions has many advantages, such as: concrete economy, use of high resistance prestressed steel, reduced labor, thermal insulation and among the most important, removal of formwork even on large spans. The fabrication involves extruding wet concrete from a moving mold after the steel has been prestressed. The required length of the precast element is obtained by cutting with circular saw. The key factors (Guide to Long-Span Concrete Floors, 2003) that influence most the vibration behavior of slabs are the following:

o The own weight of the slab

o The span of the floor

o The modulus of elasticity of the concrete used

o The stiffness of the slab

o Opening of cracks and prestress

o Live loads

In the case of prefabricated floor systems, their weight is considerably reduced towards the one of traditional slabs. Also, prestressing allows the use of long-span floors. Studies performed on precast slabs such as double tee (Yohchia Chen) have concluded very good vibration behaviour of this type of elements. Having a larger span/depth ratio than the double tees, and therefore an increased slenderness an investigation needed to be performed on the vibration behaviour of hollow-core slabs. The height, span and capable load of hollow-core slabs has increased as in can be noticed in Figure 1. If in the 70's the usual span was $10 \mathrm{~m}$, at the beginning of the 90's the maximum span has exceeded $20 \mathrm{~m}$.

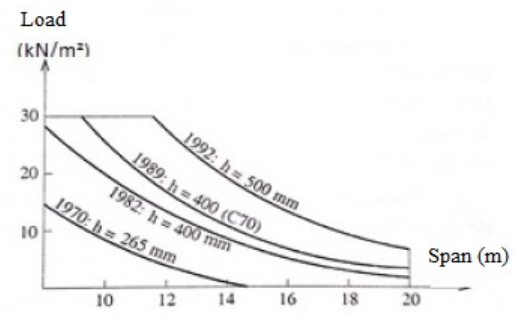

Figure 1. Span and section height -core slabs over the years (Debs, 2000)

*Corresponding author, e-mail: fratila_emil@yahoo.com 


\subsection{Experimental tests}

The measurement in experimental program have been performed using Brüel and Kjær (*) equipment on two types of slabs: $20 \mathrm{~cm}$ (HCS20) and $32 \mathrm{~cm}$ (HCS32). Their formwork and reinforcement can be observed in Figure 2. Two slits have been made at each end for local reinforcement.

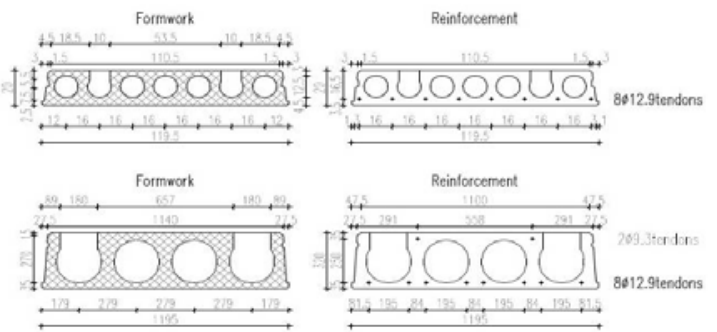

Figure 2. Types of hollow-cores measured

Extended measurements have been performed using an modal impact hammer, an accelerometer and a portable data aquisition system (Fratila, 2013). The measurement have been performed in two stages. First stage measurements were made without the concrete topping, whereas in the next stage the recordings have been carried out after the $8 \mathrm{~cm}$ mesh-reinforced concrete topping was cast in place. The natural frequencies for the first 4 modes without the concrete topping are available in Table 1 . The recorded results have shown an increase in the natural frequency due to concrete topping.

\begin{tabular}{|c|c|c|c|c|}
\hline Element & F1(hz) & F2(hz) & F3(hz) & F4(hz) \\
\hline HCS 20-1 & 7 & 24.5 & 37.5 & 60 \\
\hline HCS 20-2 & 7 & 25 & 49 & 62 \\
\hline HCS 20-3 & 8 & 26 & 46 & 59 \\
\hline HCS 32-1 & 9 & 36 & 52 & 79,5 \\
\hline HCS 32-2 & 9 & 36 & 42 & 80 \\
\hline
\end{tabular}

Table 1. Natural frequencies for the first 4 modes without the concrete topping

The first 2 modes with the $8 \mathrm{~cm}$ concrete topping cast in place have been inserted in Table 2 .

\begin{tabular}{|c|c|c|}
\hline Element & F1(hz) & F2(Hz) \\
\hline HCS 20 & 10.6 & 42.4 \\
\hline HCS 32 & 13.5 & 56.5 \\
\hline
\end{tabular}

Table 2. Natural frequencies for the first 2 modes with the concrete topping cast in place

\section{NUMERICAL MODEL}

\subsection{Finite elements modeling}

The validation of the results obtained from the experiment is an objective in many engineering related fields. This way, the future parametrical studies are based on real data. The program used in the present paper is Abaqus 6.11 developed by Dasssault Systems. For modelling the concrete 8-nodes tetraedrical C3D8R, 4-nodes-tetraedrical C3D4 and C3D10 have been used. For modelling the prestressed steel, T3D2 elements have been used. The prestressing steel was embedded in the concrete element.
The following material characteristics have been taken into account for the model:

o Elasticity modulus for precast concrete $\mathrm{E}_{\mathrm{cm}}[\mathrm{GPa}] 37$

o Compresion strength $\mathrm{C} 50 / 60$ concrete $[\mathrm{MPa}] 58$

o Poisson's coefficient for concrete C50/60 0.2

o Elasticity modulus for prestress steel $\mathrm{E}_{\mathrm{cps}}[\mathrm{GPa}] 205$

o Yeild strenght prestress steel $1679\left[\mathrm{~N} / \mathrm{mm}^{2}\right]$

o Poisson's coefficient prestress steel 0.3

o Elasticity modulus for concrete $\mathrm{E}_{\mathrm{cm}}[\mathrm{GPa}] 31$

o Compresion strength $\mathrm{C} 25 / 30$ concrete [MPa] 37

o Poisson's coefficient for $\mathrm{C} 25 / 30$ concrete 0.2

In order to ease the modelling process, the irregular surfaces from the section of the hollow-core slab elements have been approximated to straight lines as in can be seen in Figure 3 .

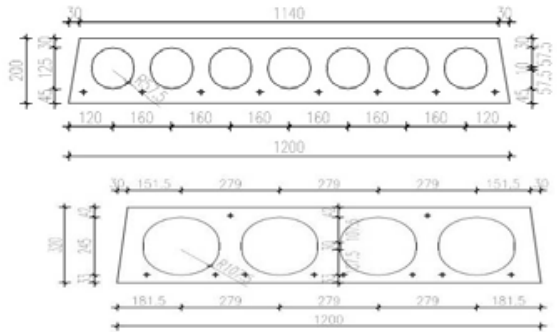

Figure 3. Section of the elements as used in modelling

For the first step without the concrete topping, the elements were considered simply supported on the entire contact length. The 3D model of the $20 \mathrm{~cm}$ hollow core slab can be seen in Figure 4.

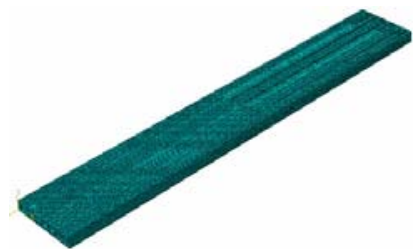

Figure 4. 3D model for a hollow-core slab

The two slits from the end of the element were kept in the 3D model as shown in Figure. The curved zones have been partitioned for correct integration as it can be seen in Figure 5.

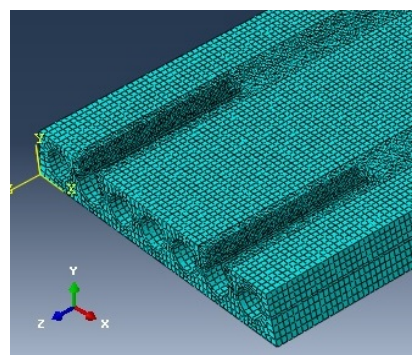

Figure 5. End zone modelling of the hollow-core slab

The values obtained with the numerical simulations for the frequencies, and also a comparison made with the results from the experiment is shown in Table 3 for the $20 \mathrm{~cm}$ slabs and in Table 4 for the $32 \mathrm{~cm}$ ones. 
$\frac{\mathrm{DE}}{\mathrm{G}}$

DE GRUYTER

\begin{tabular}{|l|c|c|c|c|}
\hline $\begin{array}{l}\text { Element } \\
\text { HCS-20 }\end{array}$ & $F_{1}$ & $F_{2}$ & $F_{3}$ & $F_{4}$ \\
\hline Experiment & 7.33 & 25.5 & 44 & 60 \\
\hline Abaqus & 8.32 & 24.7 & 42 & 53.6 \\
\hline
\end{tabular}

Table 3. Natural frequencies for the first 4 modes of HCS20

\begin{tabular}{|l|c|c|c|c|}
\hline $\begin{array}{c}\text { Element } \\
\text { HCS-32 }\end{array}$ & $\mathrm{F}_{1}$ & $\mathrm{~F}_{2}$ & $\mathrm{~F}_{3}$ & $\mathrm{~F}_{4}$ \\
\hline Experiment & 7.33 & 25.5 & 44 & 60 \\
\hline Abaqus & 8.32 & 24.7 & 42 & 53.6 \\
\hline
\end{tabular}

Table 4. Natural frequencies for the first 4 modes of HCS32

As it can be observed the differences between the experiment and the simulations are relatively small. For the second construction stage the elements have been considered simply supported on the beam whereas the concrete topping was considered continuous. A surface to surface interaction has been assigned in order to prevent slipping of the two layers of concrete poured in different stages.

The simulations were made with $8 \mathrm{~cm}$ and $6 \mathrm{~cm}$ of concrete topping to observe the changes between the two. The results obtained from the various simulations are available in Table 5...Table 8 .

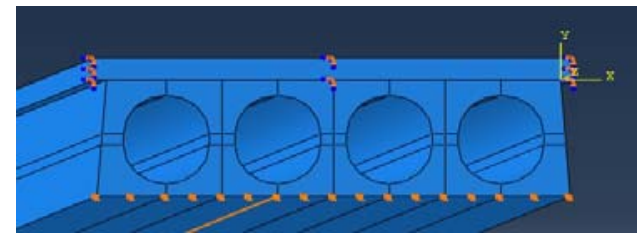

Figure 5. Slab support with concrete topping

\begin{tabular}{|l|c|c|c|c|c|}
\hline \multirow{2}{*}{$\begin{array}{l}\text { HCS32 } \\
\text { frequency }\end{array}$} & Experiment & \multicolumn{4}{|c|}{ Element length - 8cm topping } \\
\cline { 2 - 6 } & $8.75 \mathrm{~m}$ & $8.75 \mathrm{~m}$ & $10 \mathrm{~m}$ & $11 \mathrm{~m}$ & $11.5 \mathrm{~m}$ \\
\hline F1(hz) & 13.5 & 14.09 & 10.96 & 9.14 & 8.4 \\
\hline F2 (hz) & 56.5 & 40.82 & 31.85 & 26.57 & 24.5 \\
\hline
\end{tabular}

Table 5. Fundamental modes frequencies $8 \mathrm{~cm}$ topping-HCS32

\begin{tabular}{|l|c|c|c|c|}
\hline \multirow{2}{*}{$\begin{array}{l}\text { HCS32 } \\
\text { frequency }\end{array}$} & \multicolumn{4}{|c|}{ Element length $-6 \mathrm{~cm}$ topping } \\
\cline { 2 - 5 } & $8.75 \mathrm{~m}$ & $10 \mathrm{~m}$ & $11 \mathrm{~m}$ & $11.5 \mathrm{~m}$ \\
\hline F1(hz) & 13.44 & 10.40 & 8.67 & 7.55 \\
\hline F2 (hz) & 38.72 & 30.16 & 25.13 & 22.01 \\
\hline
\end{tabular}

Table 6. Fundamental modes frequencies $6 \mathrm{~cm}$ topping-HCS32

\begin{tabular}{|l|c|c|c|c|}
\hline \multirow{2}{*}{$\begin{array}{l}\text { HCS20 } \\
\text { frequency }\end{array}$} & Experiment & \multicolumn{4}{|c|}{ |lement length $-8 \mathrm{~cm}$ topping } \\
\cline { 2 - 5 } & $8 \mathrm{~m}$ & $8 \mathrm{~m}$ & $9 \mathrm{~m}$ & $10 \mathrm{~m}$ \\
\hline F1(hz) & 11 & 12.48 & 10.1 & 8.3 \\
\hline F2 (hz) & 42 & 35.9 & 28.6 & 23.6 \\
\hline
\end{tabular}

Table 7. Fundamental modes frequencies $8 \mathrm{~cm}$ topping - HCS20

\begin{tabular}{|l|c|c|c|}
\hline $\begin{array}{l}\text { HCS20 } \\
\text { frequency }\end{array}$ & \multicolumn{3}{|c|}{ Element length $-6 \mathrm{~cm}$ topping } \\
\hline & $8 \mathrm{~m}$ & $9 \mathrm{~m}$ & $10 \mathrm{~m}$ \\
\hline F1(hz) & 11.65 & 9.3 & 7.6 \\
\hline F2 (hz) & 32.7 & 26.3 & 21.3 \\
\hline
\end{tabular}

Table 8. Fundamental modes frequencies $6 \mathrm{~cm}$ topping - HCS20
The maximum frequencies of interest are the ones corresponding to the $4^{\text {th }}$ harmonic of the frequency of steps. The mode shapes for the first 4 frequencies for the bare HCS-20 elements are presented in Figure 6 ... Figure 9. The first, second and fourth mode are bending modes, whereas the third mode is a torsion mode.

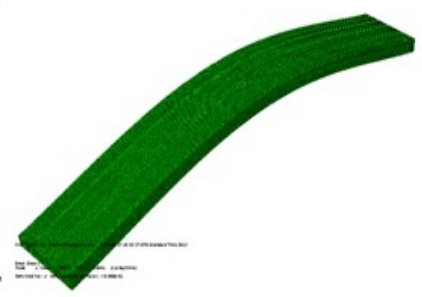

Figure 6. Mode shape 1- HCS 20

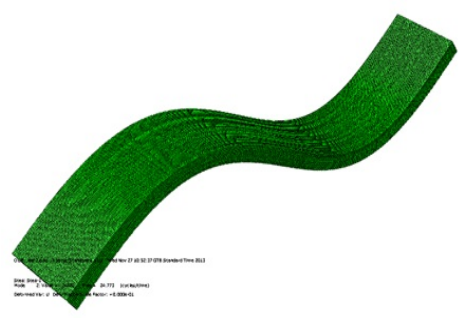

Figure 7. Mode shape 2 HCS-20

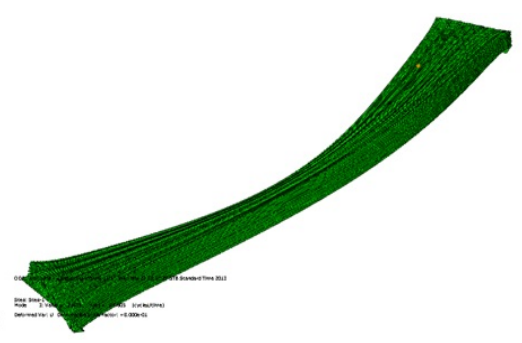

Figure 8. Mode shape 3 HCS-20

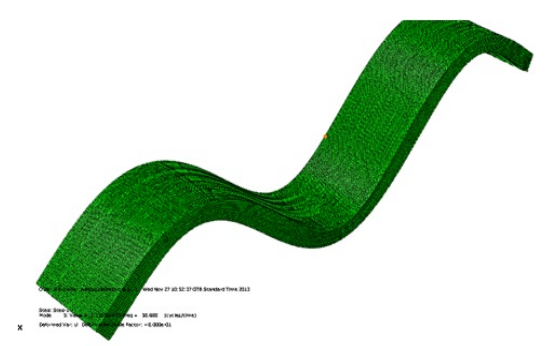

Figure 9. Mode shape 4 HCS-20

\section{RESULTS AND DISCUSSION}

\subsection{Minimum required frequency}

According to the existing literature the frequency of human footsteps $f_{s}$ lies in the $1.5-2.5 \mathrm{~Hz}$ span. For design, most commonly it is taken $1.8 \mathrm{~Hz}<f_{s}<2.5 \mathrm{~Hz}$. More accurately the frequency of normal walk span between 1.6-2.4 Hz, running 2$3.5 \mathrm{~Hz}$ and $1.5-3 \mathrm{~Hz}$ for jumping (Bachman, 1995). 
圈实

An empirical formula has been developed to asses the minimal natural frequency for a floor in order to avoid disturbing vibration caused by walking (Allen, 1993).

where:

$$
f_{n} 2.86\left[\ln \left(\frac{n_{n}}{8+w_{i}}\right)\right]
$$

- $\mathrm{k}_{\mathrm{w}}$-is a constant taken $58 \mathrm{kN}$ for residencial spaces and office floors, and $20 \mathrm{kN}$ for shopping malls,

- $\beta_{\mathrm{m}}-$ is the modal damping that varies from 0.02 for light partitions to 0.05 to heavy partition floors,

$-\mathrm{w}_{\mathrm{f}}-$ weight of the floor.

For the hollow core slabs studied the minimum frequency required is given by Table 9 .

\begin{tabular}{|l|c|c|}
\hline \multicolumn{1}{|c|}{ Element } & Weight $(\mathrm{kN})$ & $\begin{array}{c}\text { Minimum. } \\
\text { Frequency }(\mathrm{Hz})\end{array}$ \\
\hline HCS-20 no topping & 30 & 11,89 \\
\hline HCS-20 6cm & 44,4 & 10,78 \\
\hline HCS-20 8cm & 49,2 & 10,49 \\
\hline HCS-32 no topping & 43,75 & 10,81 \\
\hline HCS-32 6cm & 56,88 & 10,06 \\
\hline HCS-32 8cm & 61,25 & 9,83 \\
\hline
\end{tabular}

Table 9. Minimum frequency required for the hollow-core slabs

The calculations have been made taking into consideration the width and length of the hollow-core and a 0.03 damping coeffiecient.

\subsection{Interaction between the concrete topping and precast hollow core}

The interaction between materials cast in different stages has been investigated. According to SR EN 1992-1-1:2004, the major factors that have an influence on their interaction are the quantity of reinforcement in the joint, the rugosity of the precast element, class of concrete in the topping and the types of actions applied on the elements (Figure 10).

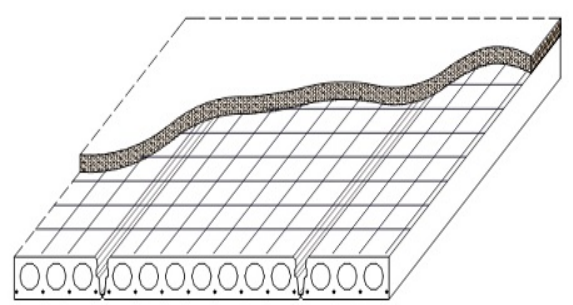

Figure 10. Precast hollow-core with mesh-reinforced concrete topping

The design value of stress in the joint between the two materials is calculated with the following equation:

$$
v_{E d i}=\beta \frac{V_{E d}}{z b_{i}}
$$

where:

$-\beta$ is the ratio between the longitudinal force in the concrete topping and the total longitudinal force as shown in Figure 11,

$$
\begin{aligned}
& -\mathrm{V}_{\mathrm{Ed}}-\text { is the shear force, } \\
& -\mathrm{z}-\text { is the lever arm, } \\
& -\mathrm{b}_{\mathrm{i}}-\text { width of the joint. }
\end{aligned}
$$
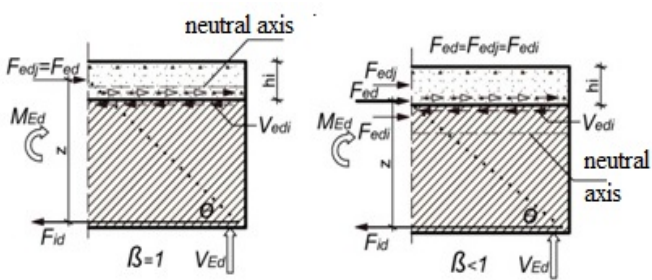

EIA. hollow-core slab

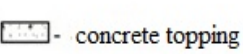

Figure 11. $\beta$ coefficient according to neutral axis position (Kiss, 2008)

The design shear resistance in the joint $v_{h_{i}}$, is computed using the following formula:

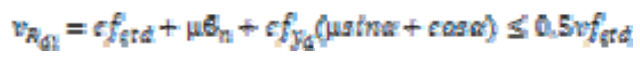

where:

- $\mathrm{f}_{\mathrm{ctd}}$ - concrete tensile design resistance,

- $\mathrm{f}_{\mathrm{yd}}$ - reinforcement yield design resistance,

-c and $\mu$ - friction related coefficients,

$-\sigma$ - compression stress in concrete,

$-\alpha-$ the angle of the reinforcement crossing the joint

$-\rho$ - the ratio between the area of reinforcement crossing the joint and the area of the joint.

The design value of the stress is compared with the shear resistance in the joint. It is important to mention that each hollow-core had steel ties embedded in the slits from the end of the precast element as shown in Figure 12.

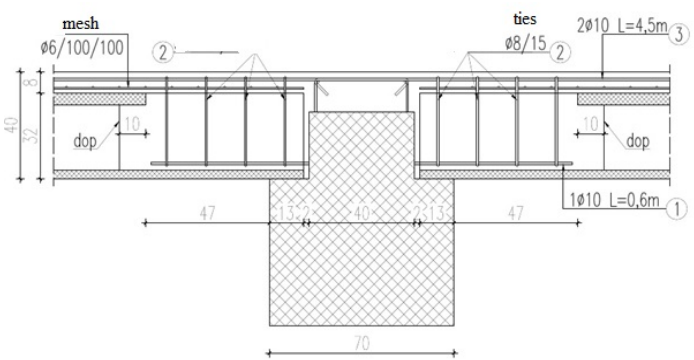

Figure 12. End reinforcement for hollow core slabs

For the element that have been the subject of the study, taking into consideration $\sigma=0.15 \mathrm{~N} / \mathrm{mm}^{2}$, the area of the steel ties in the slits at the end of the element, $c=0.5, \mu=0.7$, the value of the design shear resistance in the joint is higher than the value of the stress, therefore a connection between the two surface can be taken into account.

\section{CONCLUSIONS}

The objectives of the study were to determine the natural frequencies of the precast hollow-core slabs and to develop a finite element model. The extended measurements have shown 


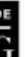

DEGRUYTER

an increase in the natural frequency of the slabs after the concrete topping was cast in place. Therefore we can take into considerations the behaviour of the connection between the precast element and the concrete topping, which is also justified by calculations.

However, the study does not contain data about the long term vibration behaviour of the element. Taking into consideration the existing literature which recommends the fundamental frequency of the slabs to be higher than the fourth harmonic of the human footsteps which has been established to be $8 \mathrm{~Hz}$, the elements tested with concrete topping meet the vibration standard (Zivanovic, 2005).

The comparison made with the criteria proposed by Allen for the minimum frequency, shows that some methods are safer than others. According to the values obtained from the parametrical study there is a notable defence between the frequencies of the elements depending on their concrete topping.

It is clearly shown that the use of a higher concrete topping allows higher spans to be achieved, through the existing difference in the frequencies.

\section{ACKNOWLEDGMENT}

This paper was supported by the project "Improvement of the doctoral studies quality in engineering science for development of the knowledge based society-QDOC" contract no. POSDRU/107/1.5/S/78534, project co-funded by the European Social Fund through the Sectorial Operational Program Human Resources 2007-2013.

\section{REFERENCES}

D.E. Allen, T. M. (1993, Fourth Quarter). Design criterion for vibration due to walking. American Institute of Steel Construction, pg. 117-129.

Debs, M. E. (2000). Precast concrete: Fundamentals and applications. Sao Carlos School of Engineering.

E. Fratila, Z. K. (2013). Experimental modal analysis of hollow core slabs. 13th International Scientific Conference VSU. Sofia.

Kjær, B. a. www.bksv.com. (viewed at 10.03.2011)

Yohchia Chen, A. A. (2005). Vibration characteristics of double tee building floors. Precast Concrete Institute.

Z. Kiss, T. O. (2008). Design of concrete structures according to SR EN 1992-1. Abel.

Avitable, P. (2001). Experimantal modal analisys, a simple nonmathematical presentation.

Brownjohn J.M.W., Z. X. (2001). Human dynamics and floor vibration. Singapore: The Eighth East Asia-Pacific Conference on Structural Engineering and Construction.
BS 6472: 1992 Guide to evaluation of human exposure to vibration in buildings (1 Hz to $80 \mathrm{~Hz}$ ). (1992). British Standard Institution.

(2003). Guide to Long-Span Concrete Floors. Cement and Concrete Association of Australia.

P.C.I. Manual for the Design of Hollow Core Slabs. (n.d.). Chicago: Precast/Prestressed Cocrete Institute.

Z. Kiss, t. O. (2008). Design of concrete structures according to SR EN 1992-1. Abel.

Zivanovic S, P. A. (2005). Vibration serviceability of footbridges under human-induced excitation: a literature review. (279) 